Uluslararası Sosyal Bilgilerde Yeni Yaklașımlar Dergisi, 2021, 5(1), 177-190

International Journal of New Approaches in Social Studies, 2021, 5(1), 177-190

\title{
Sınıf Öğretmeni Adaylarının Yaratıcı Kişilik Özellikleri ile Yaratıcılığı Destekleme Becerileri Arasındaki İlişkinin İncelenmesi
}

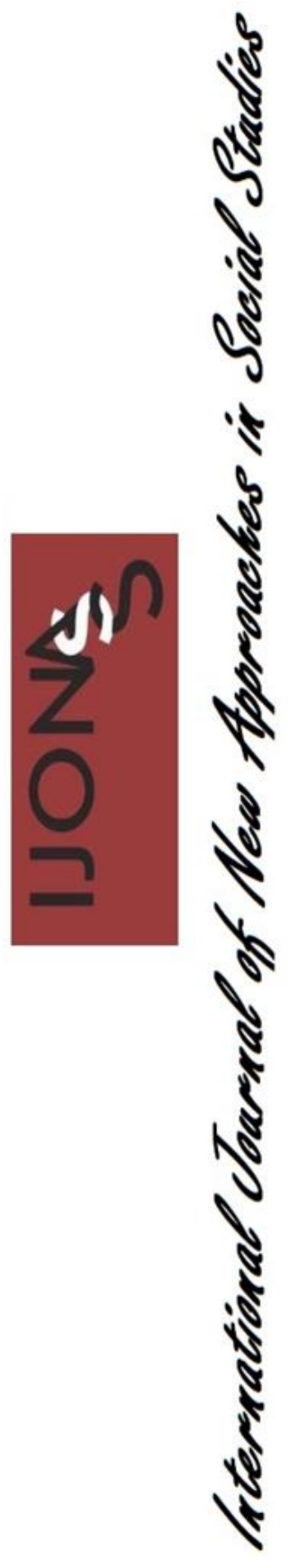

\author{
Dila LEYLAK ${ }^{1 *}$ (i) \& Serkan SAY ${ }^{2}$
}

Gönderilme Tarihi: 08 Nisan $2021 \quad$ Kabul Tarihi: 26 Mayı 2021

DOI: $10.38015 /$ sbyy. 911805

\begin{abstract}
$\ddot{O}_{z:}$
Bu araştırmanın amacı sınıf ögretmeni adaylarının yaratıcı kişilik özellikleri ile yaratıcılığı destekleme becerileri arasındaki ilişkiyi incelemektedir. Araştırmada bu ilişkiye ek olarak; sınıf ögretmeni adaylarının yaratıcı kişilik özellikleri ve yaratıcılı̆̆ destekleme becerilerileri; sınıf düzeyi, cinsiyet ve mezun olunan okul türü değişkenlerine göre incelenmiştir. Araştırmanın çalışma grubunu, Akdeniz bölgesinde yer alan bir devlet üniversitesinin eğitim fakültesi sınıf öğretmenliği bölümünde, 1, 2, 3 ve 4. sınıf düzeylerinde öğrenim gören 244 sını öğretmeni adayı oluşturmaktadır. Nicel araştırma yöntemlerinden tarama modeline göre tasarlanan çalışmada veriler; araştırmacılar tarafindan geliştirilen "Kişisel Bilgi Formu", Şahin \& Danışman (2007) tarafindan geliştirilen "Yaratıcı Kişilik Özellikleri Ölçeği " ve Soh (2000) tarafindan geliştirilen ve Dikici (2013) tarafindan Türkçe’ye uyarlanan "Yaratıcılı̆̆l Destekleyen Öğretmen Indeksi Ölçeği" aracılı̆̆ ile toplanmıştır. Araştırmadan ulaşılan sonuçlara göre; sınıf öğretmeni adaylarının yaratıcı kişilik özellikleri ile yaratıcılı̆̆ destekleme becerileri arasında pozitif yönde, yüksek düzeyde anlamlı bir ilişki olduğu görülmektedir. Sınıf ögretmeni adaylarının yaratıcı kişilik özellikleri için, cinsiyete ve mezun olunan okul türüne göre anlaml bir fark görülmemekte, sinıf düzeyine göre ise 1-3, 1-4 ve 2-3, 2-4 sınıf düzeyleri arasında anlaml bir fark görülmektedir. Sinıf ögretmeni adaylarının yaratıcllı̆̆ destekleme becerileri için ise cinsiyete ve mezun olunan okul türüne göre yine anlaml bir fark görülmemekte, sınıf düzeyine göre ise 1-4 ve 2-4 sinıf düzeyleri arasında anlamlı bir fark görülmektedir. Araştırmadan elde edilen sonuçlar benzer araştırma sonuçları ile karşılaştırılmış, tartışılmış ve yorumlanmıştır. Araştırmadan elde edilen bulgular ışı̆̆ında; sınıf öğretmenliği lisans programına öğretmen adaylarının yaratıcılık düzeyinin gelişimine katkı sağlayacak zorunlu veya seçmeli derslerin eklenmesi önerilebilir.
\end{abstract}

Anahtar Kelimeler: Sınıf öğretmeni adayları, yaratıcılık, yaratıcılı̆̆ı destekleme.

\begin{abstract}
:
The aim of this study is to examine the relationship between creative personality traits of classroom teacher candidates and their ability to support creativity. In addition to this relationship, the creative personality skills and skills of classroom teacher candidates were examined according to the variants of class level, gender and type of school graduated. For this purpose, 1, 2, 3 and 4 in the Department of primary education of the faculty of education of a state university located in the Mediterranean region. 244 classroom teachers who study at grade levels Constitution the candidate. Quantitative research methods are designed according to the scanning model, which was developed by the researcher, the data in the first study, "personal information
\end{abstract}

\footnotetext{
${ }^{1}$ Mersin Üniversitesi, Türkiye, ORCID ID: 0000-0002-5597-2048

${ }^{2}$ Mersin Üniversitesi, Türkiye, ORCID ID: 0000-0002-0917-8660

"SorumluYazar (Corresponding Author): dilaleylak@gmail.com
} 
form", the Şahin and Danışman (2007) developed by the "creative personality traits scale" and and the "Teacher Index Scale Supporting Creativity" developed by Soh (2000) and adapted to Turkish by Dikici (2013) were collected. to the results of the research; it seems that there is a positive, high-level meaningful relationship between the creative personality traits of the classroom teacher candidates and their ability to support creativity. Creative personality traits for prospective teachers, by school type and gender, a significant difference can be seen that note, according to the class level 1-3, 1-4 and 2-3, 2-4, there is a significant difference between grade levels. By supporting prospective teachers for the skills of creativity, gender and school type is not a significant difference can be seen again, there is a significant difference between grade levels 1-4 and 2-4 according to the class level. The results of the research were compared, discussed and interpreted with similar research results. In light of the results obtained from the research, it may be recommended to add compulsive or selective courses to the license program of classroom teaching that will contribute to the development of the level of creativity.

Keywords: Classroom teacher candidates, creativity, supporting creativity.

\section{GíRiș}

Ülkeler, varlıklarını ve refahlarını sürdürebilmek amacı ile sürekli olarak gelişim gösterme ve çağdaş medeniyetler seviyesine ulaşma gayretindedir. Bu yolda en kilit noktalardan biri ise kuşkusuz eğitimdir. Eğitim yolu ile toplumlar ihtiyaç duydukları devinimi gerçekleştirecek donanıma sahip, nitelikli bireyler yetiştirebilmeyi hedeflemektedir (İlter \& Köksalan, 2011). $\mathrm{Bu}$ bilgi ve becerileri bireylere kazandırma sürecinde öğretmenlerin rolü büyük önem taşımaktadır (Turan \& diğ., 2016). Öğretmenler; eğitim süreci boyunca gösterdikleri davranışlar ve gerçekleştirdikleri öğretimler ile öğrencilerinin hem akademik hayatı hem de kişisel özellikleri üzerinde önemli etkiler yaratabilmektedir (Cerit, 2008). Yetiștirilen bireylerin eğitim sürecinde kazandığı nitelikler öğretmenlerin sahip olduğu özellikler ile paralellik göstermektedir (Kılıç, 2006). Çelikten ve diğ. (2005) öğretmenlerin özelliklerinin yetiştirdikleri bireylerin özüne de sirayet ettiğini belirtmişler ve öğretmenleri insan kişiliğini inşa eden ve şekillendiren sanatçılar olarak nitelendirmişlerdir. Türer (2009) ise öğretmenlik mesleği için, diğer bütün meslek gruplarına yönelik birey yetiştirmede kilit noktada olması nedeni ile "mesleklerin mesleği”" ifadesini kullanmıştır. Bu misyonları nedeni ile öğretmenlerin sahip oldukları nitelikler; eğitim sonrası birçok farklı alana yönelen öğrencilerinin mesleklerinde gerçekleştirecekleri uygulamaları, atılımları ve uzun vadede toplumun ekonomik ve sosyal yapısını da etkilemektedir. İçinde bulunduğumuz 21. yüzyılda toplumların kalkınma hedeflerine ulaşmak için yetiştirmek istediği bireylerde bulunması beklenen belli özellikler vardır. 21. yüzyıl becerileri olarak ifade edilen bu özellikler ile ilgili birden fazla sınıflama bulunmaktadır. Yapılan sınıflamaların genelinde ise; yaratıcı düşünme, eleştirel bakış açısı, problem çözebilme ve iş birliği gibi becerilere vurgu yapılmaktadır. (Belet Boyacı \& Güner Özer, 2019).

21. yüzyıl becerilerinden biri olan yaratıcılık, hayal gücü ile desteklenen özgün düşünceler ortaya koyma becerisidir (Kılıç \& diğ. 2018). Torrance (1977) yaratıcılığı; bir problemi hissetme, tanımlama, probleme yönelik denenceler oluşturup test ederek elde edilen sonuçlar 1şı̆̆ında ortaya bir ürün çıkarma süreci olarak tanımlamıştır. Yaratıcılık; problemlere farklı bakış açıları getirerek yeni çözüm yolları geliştirmek için gereklidir (Koray, 2004). Kısa zamanda yeni ve yaratıcı fikirler elde eden ve bu fikirlerini uygulamaya geçiren bireylere, toplumlar tarafından ihtiyaç duyulmaktadır (Temizkan, 2011).

Ülkemizde Milli Eğitim Bakanlığının gündeminde ve öğretim programlarının içeriğinde de yaratıcılık becerisine değinilmiştir. 1973 yılında yayınlanan 1739 sayılı Milli Eğitim Genel Kanunu'nda “Türk Milli Eğitiminin genel amacı, Türk Milletinin bütün fertlerini; beden, zihin, ahlak, ruh ve duygu bakımlarından dengeli ve sağllklı şekilde gelişmiş bir kişiliğe ve karaktere, 
hür ve bilimsel düşünme gücüne, geniş bir dünya görüşüne sahip, insan haklarına saygıll, kişilik ve teşebbüse değer veren, topluma karşı sorumluluk duyan; yapıcı, yaratıcı ve verimli kişiler olarak yetiştirmek.” ifadesi yer almaktadır (MEB, 1973). 2011 yılında Milli Eğitim Bakanlığı tarafından yayınlanan 21. yüzyıl öğrenci profili çalışmasında, öğrencilerin farklı ve yaratıcı düşünen bireyler olarak yetiştirilmesinin önemi vurgulanmaktadır (MEB, 2011). 2018 yılında güncellenen öğretim programlarında Türkiye Yeterlilikler Çerçevesinde (TYÇ) sekiz adet yetkinlik belirlenmiştir. Bu yetkinliklerden biri olan inisiyatif alma ve girişimcilik yetkinliğinin açıklamasında "Yaratıcılık, yenilik ve risk almanın yanında hedeflere ulaşmak için planlama yapma ve proje yönetme yeteneğini de içerir.” ifadesi bulunmaktadır (MEB, 2018). Yine 2018 Fen Bilimleri Öğretim Programı kapsamında yaratıcılık becerisi; Fen Bilimleri alanına özgü yaşam becerilerinden biri olarak yer almaktadır (MEB, 2018).

Toplumsal gelişim ve sürdürülebilirliğin sağlanabilmesi için büyük önem taşıyan yaratıcı bireylerin yetiştirilmesinde, yine öğretmenlerin katkısı büyüktür. Öğretmenlerden öğrencilerinin yaratıcılık becerisinin gelişimini desteklemeleri beklenmektedir (Aslan \& Arslan Cansever, 2009). Öğretmenler yaratıcı ve esnek düşünme becerisine değer vermeli, problemlere bu bakış açısında yaklaşmalıdır (Özmusul, 2012). Öğrencilerini bu anlamda motive etmeli, sınıf içerisinde yaratıcılık becerisini geliştirecek ortamlar yaratmalı, yeni fikirler için öğrencilerini teşvik etmelidir (Vale \& Barbosa, 2015). Öğretmenler; öğrenci merkezli faaliyetler, öğretimi gerçek hayat ile ilişkilendirme, öğrencilerine açık uçlu sorular yöneltme ve beceri yönetimi gibi yaratıcılığı etkileyen etkinliklerin uygulanmasına hakim olmalı ve bu bağlamda kullanılacak yöntem ve tekniklerin yeri ve zamanını doğru belirlemelidir (Trnova \& Joseph, 2014; Eragamreddy, 2013). Bu sebeple öğretmenlerin, öğrencilerinde yaratıcılığg geliştirebilmeleri ve destekleyebilmeleri için öncelikle kendilerinin yaratıcı kişilik özelliklerine sahip olmaları, daha sonra ise öğrencilerine yaratıcılıklarını geliştirebilmeleri konusunda rehberlik edebilmeleri gerekmektedir (Öztürk, 2004; Özerbaş, 2011).

Yaratıcılığın çok yüksek olduğu ilkokul çağındaki öğrencilerin eğitimini üstlenen sınıf öğretmenlerinin yaratıcılığı geliştirme sorumluluğu büyüktür (Işık, 2013). Öğrenciler tarafından rol model olarak görülen sınıf öğretmenlerinin yaratıcılığı destekleyen davranışlar göstermesi eğitim sürecinde öğrencilerin yaratıcılığını da arttırmaktadır. İlkokul süreci boyunca 4 yıl öğrencilerle bir arada olan sınıf öğretmenlerinin yaratıcılığı destekleyen davranışlarda bulunması bu nedenle önemlidir (Özel \& Bayındır, 2015). Alanyazında öğretmenlerin yaratıcılığı destekleme becerilerinin, sahip oldukları yaratıcı kişilik özelliklerinden etkilendiği belirtilmiş, sınıf öğretmenleri ile bu alanda araştırmalar gerçekleştirilmiştir (Çă̆ Adıgüzel, 2016; Pehlivan, 2019). Fakat sınıf öğretmeni adayları ile gerçekleştirilen bir çalışmaya rastlanmamıştır. Öğretmenlerin hizmet öncesi almış oldukları eğitimin meslekteki davranışları açısından önem taşıdığı bilinmektedir (Kılıç, 2006). Bu nedenle araştırmada sınıf öğretmeni adayları ile çalışılmıştır. Sınıf öğretmeni adaylarının yaratıcı kişilik özellikleri ile yaratıcılığı destekleme becerileri arasındaki ilişkinin ve bu ilişkiye ek olarak yaratıcı kişilik özellikleri ve yaratıcılığı destekleme becerilerinin sınıf düzeyi, cinsiyet ve mezun olunan okul türüne göre incelenmesinin alanyazına katkıda bulunacağı düşünülmektedir.

Ana Problem: Bu araştırmanın ana problem cümlesi; "Sınıf öğretmeni adaylarının yaratıcı kişilik özellikleri ile yaratıcılığı destekleme becerileri arasında bir ilişki var mıdır?” şeklindedir. 
Alt Problemler:

1- Sınıf öğretmeni adaylarının yaratıcı kişilik özellikleri puanlarında sınıf düzeyine göre anlamlı bir fark var midır?

2- Sınıf öğretmeni adaylarının yaratıcı kişilik özellikleri puanlarında cinsiyete göre anlamlı bir fark var midır?

3- Sınıf öğretmeni adaylarının yaratıcı kişilik özellikleri puanlarında mezun olunan okul türüne göre anlamlı bir fark var mıdır?

4- Sınıf öğretmeni adaylarının yaratıcılığı destekleme becerisi puanlarında sınıf düzeyine göre anlamlı bir fark var midir?

5- Sınıf öğretmeni adaylarının yaratıcılığı destekleme becerisi puanlarında cinsiyete göre anlamlı bir fark var midir?

6- Sınıf öğretmeni adaylarının yaratıcılığı destekleme becerisi puanlarında mezun olunan okul türüne göre anlamlı bir fark var mıdır?

\section{YÖNTEM}

\section{Araştırmanın Modeli}

$\mathrm{Bu}$ araştırma, nicel araştırma yöntemlerinden tarama modeline göre yürütülmüştür. Tarama modeli; bir durumu betimlemeyi amaç edinen ve araştırmanın konusu olan kişi, olay veya durumları sahip olduğu mevcut koşullar çerçevesinde inceleyip tanımlayan araştırma modelidir (Karasar, 2006). Bu araştırmada; sınıf öğretmeni adaylarının yaratıcı kişilik özellikleri ile öğrencilerinin yaratıcılıklarını destekleme becerileri arasındaki ilişki ve bu ilişkiye ek olarak sınıf öğretmeni adaylarının; yaratıcı kişilik özellikleri ve yaratıcılığı destekleme becerileri sınıf düzeyi, cinsiyet ve mezun olunan okul türü değişkenlerine göre incelenmiştir. Bu nedenle araştırmada tarama yöntemi kullanılmıştır.

\section{Araştırmanın Çalışma Grubu}

Araştırmanın çalışma grubunu 2020-2021 eğitim- öğretim yılında Akdeniz bölgesinde bulunan bir devlet üniversitesinde sınıf öğretmenliği bölümünde öğrenim gören 244 öğretmen aday1 oluşturmaktadır. Katılımcılar amaçlı örnekleme yöntemi ile seçilerek araştırmaya dahil edilmiştir.

\section{Veri Toplama Araçlart}

Kişisel Bilgi Formu: Araştırmacı tarafından geliştirilen Kişisel Bilgi Formunda cinsiyet, yaş, öğretmen adayının mezun olduğu lise türü, öğretmen adayının sınıf düzeyi gibi bilgiler yer almaktadir.

Yaratıcı Kişilik Özellikleri Ölçeği: Şahin ve Danışman (2007) tarafından geliştirilen yaratıcı kişilik özellikleri ölçeği; Türk kültürünü yansıtan yaratıcı kişilik özelliklerinin ölçülmesi amacı ile geliştirilmiştir. Ölçeğin geçerlik ve güvenirlik çalışmaları bir grup lise ve üniversite öğrencisi ile gerçekleştirilmiştir. Yapı geçerliğini incelemek amacı ile yapılan açımlayıcı faktör analizi sonucunda 17 maddeden oluşan dört faktörlü bir yapı elde edilmiştir. Bu faktörleri; amaç yönelimlilik, içsel motivasyon, risk alma, kendine güven ve kendine güven oluşturmaktadır. Ölçeğin alt boyutlarına ait Cronbach Alpha iç tutarlılık kat sayısı sırasıyla .65, .60, .64 ve .64 olarak belirlenmiştir Ölçek genelinin Cronbach Alfa iç tutarlılık kat sayısı ise .67 olarak belirlenmiştir. Katılımcılar maddelerin kendilerine uygunluk derecesini; (1) Kesinlikle Katılmiyorum, (2) Katılmiyorum, (3) Kararsızım, (4) Katıliyorum ve (5) Kesinlikle Katıliyorum olmak üzere 5'lilikert tipi bir derecelendirme kullanarak belirtmektedir. Toplam puan üzerinden değerlendirilen ölçekten, alınabilecek en düşük puan 17 iken en yüksek puan 
ise 85'tir. Ölçekten alınan puan değerinin yüksek olması, yaratıcı kişilik özelliğinin yüksekliğini göstermektedir (Şahin \& Danışman, 2007).

Yaratıcılı̆̆ı Destekleyen Ö̆̆gretmen İndeksi Ölçeği: Soh (2000) tarafından geliştirilen Yaratıcılığı Destekleyen Öğretmen İndeksi Ölçeği, Türkçe’ye Dikici (2013) tarafından uyarlanmıştır. Araştırmanın çalışma grubunu Niğde il merkezindeki 13 ilköğretim okulunda görev yapan 288 öğretmen oluşturmaktadır. Açımlayıcı faktör analizinde ölçeğin Türkçe formunun 33 madde ve dokuz alt boyuta sahip olduğu görülmüştür. Bu alt boyutları; bağımsızlık, bütünleştirme, yargılama, değerlendirme, güdüleme, esneklik, sorgulama, fırsat verme ve hayal kırıklığı oluşturmaktadır. Ölçeğin boyutlarından elde edilen puanın yüksek olması öğretmenin yaratıcılığı destekleyen öğretim stilinin göstergesidir. Ölçeğin ters maddesi bulunmamaktadır. Ölçeğin tamamından elde edilen Cronbach Alpha güvenirlik katsayısı ise .96’dır (Dikici, 2013).

\section{Verilerin Analizi}

Uygulanacak testlerin seçiminde; parametrik test şartları aranmış, şartları sağlayan durumlarda parametrik testler, şartları sağlamayan durumlarda ise non-parametrik testler kullanılmıştır. Elde edilen veriler istatiksel programlarda analiz edilmiştir. Sınıf öğretmeni adaylarının yaratıcı kişilik özellikleri ile yaratıcılığ destekleme becerileri arasındaki ilişkiyi tespit etmek için Pearson korelasyon kat sayısı kullanılarak Basit Doğrusal Korelasyon Testi gerçekleştirilmiştir. Sınıf öğretmeni adaylarının yaratıcı kişilik özellikleri ve yaratıcılığı destekleme becerilerinin sınıf düzeyine göre incelenmesi için Krsukal Wallis Testi uygulanmıştır. Yaratıcı kişilik özellikleri ve yaratıcılığı destekleme becerileri üzerinde sınıf düzeyine göre elde edilen farkın hangi sınıf düzeyleri arasında olduğunu tespit edebilmek amacı ile Mann- Whitney U Testi uygulanmıştır. Sınıf öğretmeni adaylarının yaratıcı kişilik özellikleri ve yaratıcılığı destekleme becerilerinin cinsiyete göre incelenmesi için Bağımsız Örneklemler T- Testi kullanılmıştır. Sınıf öğretmeni adaylarının yaratıcı kişilik özellikleri ve yaratıcılığı destekleme becerilerinin mezun olunan okul türüne göre incelenmesinde ise yine Kruskal Wallis Testi kullanılmıştır. İstatistiksel veriler gerçekleştirilirken anlamlılık düzeyi $p<, 05$ üzerinden ele alınmıştır.

\section{BULGULAR}

Çalışmanın bu bölümünde araştırmanın ana problemine ve alt problemlerine yönelik bulgulara yer verilmiştir.

$\mathrm{Bu}$ amaç ile araştırmanın ana problem durumu olan sınıf öğretmeni adaylarının yaratıcı kişilik özellikleri ile yaratıcılığı destekleme becerileri arasındaki ilişkiyi incelemek için Pearson korelasyon kat sayısı kullanılarak gerçekleştirilen Basit Doğrusal Korelasyon Testi sonuçları Tablo 1'de gösterilmiştir.

Tablo 1. Sınıf Öğretmeni Adaylarının Yaratıcı Kişilik Özellikleri ve Yaratıcılığı Destekleme Becerileri Arasındaki İlişkinin İncelenmesine Yönelik Korelasyon Testi Sonuçları

\begin{tabular}{llccc}
\hline & & $\begin{array}{c}\text { Yaratıcı Kişilik } \\
\text { Özelikleri }\end{array}$ & $\begin{array}{c}\text { Yaratıcılı̆̆ı } \\
\text { Destekleme Becerisi }\end{array}$ \\
\hline Yaratıcı Kişilik Özellikleri & $\begin{array}{l}\text { PearsonCorrelation } \\
\text { Sig. (2-tailed) }\end{array}$ & 1 &, $614^{* *}$ \\
& $\mathrm{~N}$ & 244 &, 000 \\
Yaratıcılı̆̆ı & Destekleme & PearsonCorrelation &, $614^{* *}$ & 244 \\
Becerisi & Sig. (2-tailed) &, 000 & 1 \\
& & $\mathrm{~N}$ & 244 & 244 \\
\hline
\end{tabular}


Tablo 1'de görüldüğü üzere; sınıf öğretmeni adaylarının yaratıcı kişilik özellikleri ile yaratıcılığı destekleme becerileri arasındaki ilişkiyi ortaya koymaya yönelik yapılan Basit Doğrusal Korelasyon Testi işlemi, Pearson korelasyon kat sayısı kullanılarak incelenmiştir. Yapılan analizlere göre sınıf öğretmeni adaylarının yaratıcı kişilik özellikleri ile yaratıcılığı destekleme becerileri arasında pozitif yönde, yüksek düzeyde anlamlı bir ilişki olduğu görülmektedir $(r=0,614, \mathrm{p}<0,05)$.

Çalışmada sınıf öğretmeni adayların yaratıcı kişilik özellikleri ve yaratıcılığı destekleme becerileri arasındaki ilişkiye ek olarak yaratıcı kişilik özelliklerinin sınıf düzeyine göre anlamlı bir fark gösterip göstermediği incelenmiştir. Bu amaçla Tablo 2'de sınıf öğretmeni adaylarının yaratıcı kişilik özelliklerinin sınıf düzeyine göre incelenmesine yönelik yapılan Kruskal Wallis Testi ve elde edilen anlamlı farkın hangi sınıf düzeyleri arasında olduğunu belirlemek için yapılan Mann- Whitney U Testi sonuçları gösterilmiştir.

Tablo 2. Sınıf Öğretmeni Adaylarının Yaratıcı Kişilik Özellikleri Puanlarının Sınıf Düzeylerine Göre İncelenmesine Yönelik Kruskal Wallis Testi Sonuçları

\begin{tabular}{lcccccc}
\hline Sınıf Düzeyi & N & $\begin{array}{c}\text { Sıra } \\
\text { Ortalaması }\end{array}$ & Sınıf Düzeyi & N & $\begin{array}{c}\text { Sıra } \\
\text { Ortalaması }\end{array}$ \\
\hline 1 & 54 & 88,49 & 3 & 51,015 &, 000 & $2-3,2-4$, \\
2 & 50 & 86,02 & & & & $1-3,1-4$ \\
3 & 57 & 131,57 & & & \\
4 & 83 & 160,37 & & & \\
\hline
\end{tabular}

Tablo 2'de görüldügüü üzere; sınıf öğretmeni adaylarının yaratıcı kişilik özellikleri puanlarının sınıf düzeylerine göre incelenmesine yönelik yapılan Kruskal Wallis Testi sonucunda dört farklı sınıf düzeyindeki katılımcıların yaratıcı kişilik özellikleri puanları arasında istatistiksel olarak anlamlı bir farkın olduğu görülmektedir $\left(\mathrm{x}^{2}=51,015, \mathrm{p}<, 005\right)$. Farkların hangi sınıf düzeyleri arasında olduğunu tespit etmek için yapılan Mann-Whitney U Testi ile yapılan çoklu karşılaştırma sonuçlarına göre farkların; 1-3, 1-4 ve 2-3, 2-4 sınıf düzeyleri arasında olduğu belirlenmiştir.

Sınıf öğretmeni adayların yaratıcı kişilik özellikleri ve yaratıcılığı destekleme becerileri arasındaki ilişkiye ek olarak yaratıcı kişilik özelliklerinin cinsiyete göre anlamlı bir fark gösterip göstermediği incelemiştir. Bu amaçla Tablo 3'te sınıf öğretmeni adaylarının yaratıcı kişilik özelliklerinin cinsiyete göre incelenmesine yönelik yapılan Bağımsız Örneklemler TTesti sonuçları gösterilmiştir.

Tablo 3. Sınıf Öğretmeni Adaylarının Yaratıcı Kişilik Özellikleri Puanlarının Cinsiyete Göre İncelenmesine Yönelik Bağımsız Örneklemler T-Testi Sonuçları

\begin{tabular}{lcccccc}
\hline Cinsiyet & $\mathbf{N}$ & $\overline{\mathbf{x}}$ & $\mathbf{S}$ & sd & $\mathbf{t}$ & $\mathbf{p}$ \\
\hline Kadın & 160 & 64,69 & 7,18 & 242 &, 634 &, 527 \\
Erkek & 84 & 64,05 & 8,25 & & & \\
\hline
\end{tabular}

Tablo 3'te görüldüğü üzere; sınıf öğretmeni adaylarının yaratıcı kişilik özellikleri puanlarının cinsiyete göre incelenmesine yönelik yapılan Bağımsız Örneklemler T-Testi sonucunda kadınlar $(\bar{x}=64,69 ; S=7,18)$ ve erkeklerden $(\bar{x}=64,05 ; S=8,25)$ elde edilen puanlar arasinda anlamlı bir fark olmadığı ve cinsiyetin, sınıf öğretmeni adaylarının yaratıcı kişilik özellikleri puanları üzerinde anlamlı bir etki yaratmadığı görülmektedir ( $\mathrm{p}>, 005)$. 
Sınıf öğretmeni adayların yaratıcı kişilik özellikleri ve yaratıcılığı destekleme becerileri arasındaki ilişkiye ek olarak yaratıcı kişilik özelliklerinin mezun olunan okul türüne göre anlamlı bir fark gösterip göstermediği incelenmiştir. Bu amaçla Tablo 4'te sınıf öğretmeni adaylarının yaratıcı kişilik özelliklerinin mezun olunan okul türüne göre incelenmesine yönelik yapılan Kruskal Wallis Testi sonuçları gösterilmiştir.

Tablo 4. Sınıf Öğretmeni Adaylarının Yaratıcı Kişilik Özellikleri Puanlarının Mezun Oldukları Okul Türüne Göre İncelenmesine Yönelik Kruskal Wallis Testi Sonuçları

\begin{tabular}{|c|c|c|c|c|c|c|}
\hline Sinıf Düzeyi & $\mathbf{N}$ & $\begin{array}{c}\text { Sira } \\
\text { Ortalaması }\end{array}$ & sd & $\mathbf{x}^{2}$ & p & Fark \\
\hline Anadolu Lisesi & 149 & 122,43 & 5 & 10,77 &, 056 & - \\
\hline Fen Lisesi & 4 & 147,38 & & & & \\
\hline Anadolu İmamhatip Lisesi & 17 & 117,29 & & & & \\
\hline Mesleki Tek. ve AnadoluLis. & 9 & 59,50 & & & & \\
\hline Temel Lise & 51 & 137,64 & & & & \\
\hline Diğer & 14 & 107,86 & & & & \\
\hline
\end{tabular}

Tablo 4'te görüldüğü üzere; sınıf öğretmeni adaylarının yaratıcı kişilik özellikleri puanlarının mezun oldukları okul türüne göre incelenmesine yönelik yapılan Kruskal Wallis Testi sonucunda, mezun olunan okul türünün sınıf öğretmeni adaylarının yaratıcı kişilik özellikleri puanları üzerinde anlamlı bir farka neden olmadığı görülmektedir. (p>,005).

Sınıf öğretmeni adaylarının yaratıcı kişilik özellikleri ve yaratıcılığı destekleme becerileri arasındaki ilişkiye ek olarak yaratıcılığ 1 destekleme becerilerinin sınıf düzeyine göre anlamlı bir fark gösterip göstermediği incelenmiştir. Bu amaçla Tablo 5'te sınıf öğretmeni adaylarının yaratıcılı̆̆ı destekleme becerilerinin sınıf düzeyine göre incelenmesine yönelik yapılan Kruskal Wallis Testi ve elde edilen anlamlı farkın hangi sınıf düzeyleri arasında olduğunu belirlemek için yapılan Mann- Whitney U Testi sonuçları gösterilmiştir.

Tablo 5. Sınıf Öğretmeni Adaylarının Yaratıcılığı Destekleme Becerisi Puanlarının Sınıf Düzeylerine Göre İncelenmesine Yönelik Kruskal Wallis Testi Sonuçları

\begin{tabular}{ccccccc}
\hline Sınıf Düzeyi & $\mathbf{N}$ & Sıra Ortalaması & sd & $\mathbf{x}^{\mathbf{2}}$ & $\mathbf{p}$ & Fark \\
\hline $\mathbf{1}$ & 54 & 95,18 & 3 & 26,35 &, 00 & $1-4,2-4$ \\
$\mathbf{2}$ & 50 & 98,77 & & & & \\
$\mathbf{3}$ & 57 & 130,43 & & & & \\
$\mathbf{4}$ & 83 & 149,13 & & & & \\
\hline
\end{tabular}

Tablo 5'te görüldüğü üzere; sınıf öğretmeni adaylarının yaratıcılığı destekleme becerileri puanlarının sınıf düzeylerine göre incelenmesine yönelik yapılan Kruskal Wallis Testi sonucunda dört farklı sınıf düzeyindeki katılımcıların yaratıcılığı destekleme becerileri puanları arasında istatistiksel olarak anlamlı bir fark görülmektedir $\left(x^{2}=26,35, p<, 005\right)$. Farkların hangi sınıf düzeyleri arasında olduğunu tespit etmek için yapılan Mann-Whitney U Testi ile yapılan çoklu karşılaştırma sonuçlarına göre farkların; 1-4 ve 2-4 sınıf düzeyleri arasında olduğu belirlenmiştir.

Sınıf öğretmeni adayların yaratıcı kişilik özellikleri ve yaratıcılığı destekleme becerileri arasındaki ilişkiye ek olarak yaratıcılığ 1 destekleme becerilerinin cinsiyete göre anlamlı bir fark gösterip göstermediği incelenmiştir. Bu amaçla Tablo 6'da sınıf öğretmeni adaylarının yaratıcılığı destekleme becerilerinin cinsiyete göre incelenmesine yönelik yapılan Bağımsız Örneklemler T-Testi sonuçları gösterilmiştir. 
Tablo 6.Sınıf Öğretmeni Adaylarının Yaratıcılı̆̆ı Destekleme Becerileri Puanlarının Cinsiyete Göre İncelenmesine Yönelik Bağımsız Örneklemler T-Testi Sonuçları

\begin{tabular}{lcccccc}
\hline Cinsiyet & $\mathbf{N}$ & $\overline{\mathbf{x}}$ & $\mathbf{S}$ & sd & $\mathbf{t}$ & $\mathbf{p}$ \\
\hline Kadın & 160 & 147,64 & 11,973 & 242 & 2,052 & 0,41 \\
Erkek & 84 & 143,94 & 15,705 & & & \\
\hline
\end{tabular}

Tablo 6'da görüldüğü üzere; sınıf öğretmeni adaylarının yaratıcılığı destekleme becerisi puanlarının cinsiyete göre incelenmesine yönelik yapılan Bağımsız Örneklemler T-Testi sonucunda kadinlar $(\bar{x}=147,64 ; S=11,973)$ ve erkeklerden $(\bar{x}=143,94 ; S=15,705)$ elde edilen puanlar arasında anlamlı bir fark bulunmadığı görülmektedir. ( $\mathrm{p}>, 005)$.

Sınıf öğretmeni adayların yaratıcı kişilik özellikleri ve yaratıcılığı destekleme becerileri arasındaki ilişkiye ek olarak yaratıcılığı destekleme becerilerinin mezun olunan okul türüne göre anlamlı bir fark gösterip göstermediğgi incelenmiștir. Bu amaçla Tablo 7'de sınıf öğretmeni adaylarının yaratıcılığ 1 destekleme becerilerinin mezun olunan okul türüne göre incelenmesine yönelik yapılan Kruskal Wallis Testi sonuçları gösterilmiştir.

Tablo 7.Sınıf Öğretmeni Adaylarının Yaratıcılığı Destekleme Becerisi Puanlarının Mezun Oldukları Okul Türlerine Göre İncelenmesine Yönelik Kruskal Wallis Testi Sonuçları

\begin{tabular}{lcccccc}
\hline \multicolumn{1}{c}{ Sinıf Düzeyi } & N & Ortalaması & Sd & $\mathbf{x}^{\mathbf{2}}$ & $\mathbf{p}$ & Fark \\
\hline Anadolu Lisesi & 149 & 124,06 & 5 & 8,408 &, 135 & - \\
Fen Lisesi & 4 & 123,88 & & & \\
Anadolu İmamhatip Lisesi & 17 & 135,50 & & & \\
Mesleki Tek. ve AnadoluLis. & 9 & 81,61 & & & \\
Temel Lise & 51 & 131,04 & & & \\
Diğger & 14 & 84,93 & & & \\
\hline
\end{tabular}

Tablo 7'de görüldüğü üzere; sınıf öğretmeni adaylarının yaratıcılığı destekleme becerisi puanlarının mezun oldukları okul türlerine göre incelenmesine yönelik yapılan Kruskal Wallis Testi sonucunda, mezun olunan okul türünün sınıf öğretmeni adaylarının yaratıcılığı destekleme becerisi puanları üzerinde anlamlı bir farka neden olmadığı görülmektedir $(p>, 005)$.

\section{SONUÇ, TARTIŞMA VE ÖNERILER}

$\mathrm{Bu}$ araştırmada ana probleme yönelik olarak sınıf öğretmeni adaylarının yaratıcı kişilik özellikleri ile yaratıcılığı destekleme becerileri arasındaki ilişki incelenmiştir. Bu ilișkiye ek olarak alt problemler başlığı altında; sınıf öğretmeni adaylarının yaratıcı kişilik özellikleri, sınıf düzeyi, cinsiyet, mezun olunan okul türü ve sınıf öğretmeni adaylarının yaratıcılığı destekleme becerileri sınıf düzeyi, cinsiyet ve mezun olunan okul türüne göre incelenmiştir.

Araştırmanın problem cümlesi doğrultusunda; sınıf öğretmeni adaylarının yaratıcı kişilik özelliklerine sahip olma düzeyleri ile yaratıcılığı destekleme becerileri arasında pozitif yönde yüksek bir ilişki olduğu görülmektedir (Tablo 1). Ülkemizde konu üzerine öğretmenler ile yapılan bazı çalışmalar bulunmaktadır. Çă̆ Adıgüzel'in (2016) ve Pehlivan'ın (2019) çalışmalarında da elde edilen bu bulguyu destekleyecek şekilde sınıf öğretmenlerinin yaratıcılık düzeylerinin, öğrencilerinde yaratıcılığı destekleme düzeyleri ile ilişkili olduğu görülmüştür. Elde edilen bu bulgu Lee'nin (2013) öğretmen adaylarının yaratıcılık özelliklerinin öğrencilerinde yaratıcılık becerisini destekleyici davranışlar sergilemeleri ile ilişkili olduğu görüşünü de desteklemektir. Bu sonuçlara göre; öğretmenlerin ve geleceğin öğretmenleri olan öğretmen adaylarının, ülkenin ihtiyaç duyduğu yaratıcı bireyleri yetiştirebilmeleri için, yaratıcı 
kişilik özelliklerine sahip olmaları gerektiği söylenebilir. Öğretmenlik mesleğine hazırlık süreçlerinin öğretmen adaylarının tabi oldukları lisans programlarında ve öğrenim süreçlerinin bütününde yaratıcı kişilik özelliklerini geliştirecek içerikler ile desteklenmesi bu açıdan önemlidir.

Çalışmanın birinci alt problemine yönelik olarak sınıf öğretmeni adaylarının yaratıcı kişilik özellikleri; sınıf düzeyi değişkenine göre incelendiğinde anlamlı bir fark bulunmakta ve bu farkın 1-3, 1-4 ve 2-3, 2-4 sınıf düzeyleri arasında olduğu görülmektedir (Tablo 2). Elde edilen bu bulgu doğrultusunda, sınıf öğretmeni adaylarının eğitim fakültesinde geçirdikleri sürenin, yaratıcı kişilik özelliklerini arttıracak nitelikte olduğu yorumu yapılabilir. Öğretmen adaylarının sınıf düzeyleri arttıkça yaratıcılık düzeylerinin de yükselmekte olduğu görülmüştür. $\mathrm{Bu}$ durumun, sınıf öğretmenliği lisans programında 3. sınıftan itibaren öğretim derslerinin yoğunluk kazanması ve sınıf öğretmeni adaylarının Okul Deneyimi ve Öğretmenlik Uygulaması 1-2 derslerini alarak staj yapmaya başlamaları ile birlikte, daha sık ders planı ve derslere yönelik etkinlik tasarımları yapmalarından kaynaklı olabileceği düşünülebilir. Yapılan diğer çalışmalarda farklı bazı sonuçlar da mevcuttur. Türkmen'in (2014) çalışmasında, sınıf düzeyinin yaratıcılık üzerinde anlamlı bir farka neden olduğu ve bu farkın 1-4. sınıf düzeyleri arasında fakat 1. sinıfların lehine bulunduğu görülmektedir. Durnacı ve Ültay'ın (2020) çalışmalarında ise; 1 . sınıftan 3. sınıfa kadar olan sürede sınıf öğretmeni adaylarının yaratıcılık seviyeleri artış gösterse de sınıf düzeyinin yaratıcılık üzerinde anlamlı bir farka neden olmadığı görülmektedir. $\mathrm{Bu}$ sonuçlara göre yaratıcı kişilik özellikleri sınıf düzeylerine göre incelendiğinde farklı araştırmalarda farklı sonuçlar elde edilebileceği görülmektedir. $\mathrm{Bu}$ durumda farklı çalışma grupları ile gerçekleştirilen çalışmalarda; öğrencilerin okudukları üniversite, fakülte ortamı, sınıf düzeyleri arasındaki etkileşim ilişkisi, okudukları üniversitede sınıf öğretmenliği lisans programındaki derslerin işlenme biçimleri gibi etkenlere bağlı olarak sınıf düzeyi değişkeninin yaratıcı kişilik özellikleri üzerinde farklı etkiler gösterebileceği düşünülebilir.

Çalışmanın ikinci alt problemine yönelik olarak sınıf öğretmeni adaylarının yaratıcı kişilik özellikleri, cinsiyet değişkenine göre incelendiğinde anlamlı bir fark elde edilmediği görülmektedir (Tablo 3). Öğretmen adayları ve öğretmenlerin yaratıcılık düzeylerini belirlemek için yürütülen bazı araştırmalarda bu bulguyu destekleyecek şekilde cinsiyet değişkenine göre bir fark görülmeyen sonuçlar mevcuttur. İşleyen ve Küçük'ün (2013); Polat ve Kontaş'ın (2018) çalışmalarında yaratıcılık üzerinde cinsiyete göre anlamlı bir fark bulunmadığı görülmektedir. Bununla birlikte alanyazında yaratıcılık düzeyinin cinsiyete göre farklılık gösterdiğine yönelik sonuçlar da mevcuttur. Gök ve Erdoğan'nın (2011); Altın'ın (2010) çalışmalarında; yaratıcılık üzerinde cinsiyete göre anlamlı bir farka rastlanmış ve kadınların yaratıcılık düzeyleri, erkeklere göre daha yüksek bulunmuştur. Araştırmanın bulgularını destekleyen ve araştırmanın bulgularından aksi bulgular elde edilen başka çalışmaların bulunması; araștırmalardaki çalıșma grubunun kiși sayısının farklılık göstermesi, verilerin farklı ölçekler kullanılarak elde edilmiş olması, çalışmaya katılan öğretmen adaylarının sınıf düzeylerinin farklı olması gibi etkenler sebebi ile olabilir.

Çalışmanın üçüncü alt problemine yönelik olarak sınıf öğretmeni adaylarının yaratıcı kişilik özellikleri, mezun olunan okul türüne göre incelendiğinde anlamlı bir fark bulunamamıştır (Tablo 4). Elde edilen puanlara göre yaratıcı kişilik özellikleri puanı en yüksek grubun 147,38 sıra ortalaması ile Fen Lisesi mezunu öğretmen adayları olduğu saptanmıştır. Gülel'in (2006) çalışmasında mezun olunan okul türü değişkenine göre anlamlı bir farka rastlamadığı görülmektedir. İlgili çalışmada da belirtildiği gibi bu durumun; sınıf öğretmeni adaylarının, 
lisede farklı okul türlerinde eğitim alsalar da aynı eğitim sistemi içinde bulunmaları ve üniversite hazırlık döneminde benzer süreçlerden geçmeleri ile açıklanabilmesi mümkündür.

Çalışmanın dördüncü alt problemine yönelik olarak sınıf öğretmeni adaylarının yaratıcılığı destekleme becerisi puanları sınıf düzeylerine göre incelendiğinde anlamlı bir fark bulunmakta ve bu farkın 1-4 ve 2-4 sınıf düzeyleri arasında olduğu görülmektedir (Tablo 5). Bu bulgulara göre; 3. Sınıftan itibaren almaya başladıkları öğretim derslerinin, Okul Deneyimi ve Öğretmenlik Uygulaması 1-2 dersleri ile stajlarını gerçekleştirdikleri sürede yapmış oldukları ders planı ve ders anlatımlarında kazandıkları deneyimlerin, öğrenciler ile bir arada olma, kıdemli sınıf öğretmenlerini gözlemleme imkanı bulma ve sınıf ortamı tecrübesi gibi kazanımlarının artması sonucunda sınıf öğretmeni adaylarının, yaratıcılığı destekleme becerilerinin de arttığı söylenebilir. Daha önce yapılan araştırmalar incelendiğinde, sınıf öğretmeni adaylarının yaratıcılığı destekleme becerilerini sınıf düzeyine göre inceleyen bir araştırmaya rastlanmamıştır. Bu durum, elde edilen bulgunun önemini ortaya koymaktadır.

Çalışmanın beşinci alt problemine yönelik olarak sınıf öğretmeni adaylarının yaratıcılığı destekleme becerisi puanları cinsiyete göre incelendiğinde anlamlı bir fark bulunmamıştır (Tablo 6). Bu bulgu; Yenilmez ve Yolcu'nun (2007) öğretmenler ile gerçekleştirmiş oldukları çalışmalarında elde ettikleri bulgular ile uyuşmaktadır. İlgili çalışmada da cinsiyet faktörünün öğretmenlerin yaratıcılığ destekleme becerisi düzeylerinde bir farka neden olmadığ görülmektedir.

Çalışmanın altıncı alt problemine yönelik olarak sınıf öğretmeni adaylarının yaratıcılığ destekleme becerisi puanlarının mezun oldukları okul türlerine göre incelendiğinde yine anlamlı bir fark bulunmamaktadır (Tablo 7). Daha önce yapılan araştırmalar incelendiğinde, sınıf öğretmeni adaylarının yaratıcılığı destekleme becerilerini mezun oldukları okul türüne göre inceleyen bir araştırmaya rastlanmamıştır. Bu durum, yine elde edilen bulgunun önemini ortaya koymaktadır.

Araştırmada elde edilen bulguların alanyazın ile ilişkili olduğu görülmektedir. Sınıf öğretmeni adayları ile gerçekleştirilen araştırmada, daha önce başka çalışmalarda rastlanmayan bazı sonuçlara da ulaşılmıştır. Bu nedenle çalışmanın, bundan sonraki araştırmalar için de kaynak teşkil edeceği düşünülmektedir. Araştırmadan elde edilen bulgular ışığında; sınıf öğretmenliği lisans programına yaratıcılık becerisinin gelişimine katkı sağlayacak zorunlu veya seçmeli derslerin eklenmesi önerilebilir.

\section{KAYNAKÇA}

Altın, B. (2010). İlköğretimde görevli ögretmenlerin örgütsel bă̆llllklarıyla yaratıcllkklarl iliş̧kisi [Yüksek lisans tezi]. Maltepe Üniversitesi, İstanbul.

Aslan, N., \& Arslan Cansever, B. (2010). Eğitimde yaratıcılığın kullanımına ilişkin öğretmen tutumları. TÜBAV Bilim Dergisi, 2(3), 333-340.

Belet Boyacı, Ş.D., \& Güner Özer, M. (2019). Öğrenmenin geleceği: 21. yüzyıl becerileri perspektifiyle Türkçe dersi öğretim programları. Anadolu Journal of Educational Sciences International, 9(2), 708-738.

Cerit, Y. (2008). Öğretmen kavramı ile ilgili metaforlara ilişkin öğrenci, öğretmen ve yöneticilerin görüşleri. Türk Eğitim Bilimleri Dergisi, 4(6), 693-712.

Çağ Adıgüzel, D. (2016). Sinıf öğretmenlerinin yaratıcı düşünme becerileri ile öğretmen davranışlarının ögrencilerin yaratıcı düşünme becerilerinin gelişimine katkısı arasındaki ilişski. [Yüksek lisans tezi]. Pamukkale Üniversitesi Eğitim Bilimleri Enstitüsü, Denizli. 
Çelikten, M., Şanal, M., \& Yeni, Y. (2005). Öğretmenlik mesleği ve özellikleri. Erciyes Üniversitesi, Sosyal Bilimler Enstitüsü Dergisi, 19, 207-237.

Dikici, A. (2013). Yaratıcılığı destekleyen ilköğretim öğretmenleri indeksi ölçeği’nin Türkçeye uyarlanması. Kuram ve Uygulamada Eğitim Bilimleri, 13(1), 307-324.

Durnacı, Ü., \& Ültay, N. (2020). Sınıf öğretmeni adaylarının eleştirel ve yaratıcı düşünme eğilimleri. Turkish Journal of Primary Education, 5(2), 75-97.

Eragamreddy, N. (2013). Teaching creative thinking skills. International Journal of English Language \& Translation Studies, 1(2), 124-145.

Gök, B., \& Erdoğan T. (2011). Sınıf öğretmeni adaylarının yaratıcı düşünme düzeyleri ve eleştirel düşünme eğilimlerinin incelenmesi. Ankara Üniversitesi Eğitim Bilimleri Fakültesi Dergisi, 44 (2), 29-51.

Gülel, G. (2006). Sınıf öğretmeni adaylarının yaratıcılık düzeylerinin çeşitli değişkenler açısından incelenmesi. [Yüksek lisans tezi]. Pamukkale Üniversitesi, Sosyal Bilimler Enstitüsü, Denizli.

Işık, D.A. (2013). Sınıf öğretmenlerinin yaratıcı bireyler yetiştirmede görev ve sorumlulukları, International Journal Of Social Science, 6(6), 585-601.

İlter, İ., \& Köksalan, B. (2011). Sınıf öğretmeni adaylarının öğretmenlik mesleğine olan tutumları. Fırat Üniversitesi Sosyal Bilimler Dergisi, 21(1), 113-128.

İşleyen, T., \& Küçük, B. (2013). Öğretmen adaylarının yaratıcı düşünme düzeylerinin farklı değişkenler açısından incelenmesi/Examining. Mustafa Kemal Üniversitesi Sosyal Bilimler Enstitüsü Dergisi, 10(21), 199-208

Karasar, N. (2006). Bilimsel araştırma yöntemi. Nobel Yayın Dağıtım.

Kılıç, A. (2006). Öğretmen adaylarının öğretmenlik becerilerini uygulama ve gözleme düzeyleri, Manas Üniversitesi Sosyal Bilimler Dergisi, 16(8), 155-168.

Kılıç, F., Yavuz Konokman, G., \& Yanpar Yelken, T. (2018). Yaratıcı öğrenme ortamı değerlendirme ölçeği geliştirme: açımlayıcı ve doğrulayıcı faktör analizi. Kastamonu Eğitim Dergisi, 26(4), 1359-1370.

Koray, Y. (2004). Fen eğitiminde yaratıcı düşünmeye dayalı öğrenmenin öğretmen adaylarının yaratıcılık düzeylerine etkisi. Kuram ve Uygulamada Ĕ̈itim Yönetimi, 40(40), 580-599.

Lee, R. (2013). Pre-service teachers' personality traits and creative behaviors as predictors of their support of children's creativity. [Doctoral dissertation]. University of Florida, Gainesville, Florida, A.B.D.

Milli Eğitim Bakanlığı (1973). Milli eğitim temel kanunu. Ankara

Milli Eğitim Bakanlığı. (2018). Fen Bilimleri dersi ögretim programı. Ankara

Özel, A. \& Bayındır, N. (2015). Sınıf öğretmenlerinin öğrencilerde yaratıcılığı geliştirmeye yönelik öğretimsel davranışları. Uluslararası Türk Eğitim Bilimleri Dergisi, 2015(5), 348-358 .

Özerbaş, M.A. (2011). Yaratıcı düşünme öğrenme ortamının akademik başarı ve bilgilerin kalıcılığa etkisi. Gazi Eğitim Fakültesi Dergisi, 31(3), 675-705.

Özmusul, M. (2012). Öğretmen eğitiminde yaratıc1lık ve inovasyon. Kastamonu Eğitim Dergisi, 20(3), $731-746$.

Öztürk, Ş. (2004). Eğitimde yaratıcı düşünme. Ondokuz Mayıs Üniversitesi Eğitim Fakültesi Dergisi, $18,77-84$.

Pehlivan, N. (2019). Sınıf öğretmenlerinin yaratıcılık düzeyleri ile yaratıcılı̆̆ destekleme düzeyleri arasındaki ilişkinin incelenmesi. [Yüksek lisans tezi]. Sakarya Üniversitesi Eğitim Bilimleri Enstitüsü, Sakarya.

Polat, M., \& Kontaş, H. (2018). Sınıf öğretmenlerinin yaratıcılık düzeylerinin incelenmesi. Abant Izzet Baysal Üniversitesi Eğitim Fakültesi Dergisi, 18(3), 1702-1721.

Şahin, F., \& Danışman, Ş. (2017). Yaratıcı kişilik özellikleri ölçeği: güvenirlik ve geçerlik çalışması. Karabük Üniversitesi Sosyal Bilimler Enstitüsü Dergisi, 7(2), 747-760

Temizkan, M. (2013). Türkçe öğretiminde yaratıcı düşünmeyi geliştirme bakımından Nasreddin Hoca fkraları. Mustafa Kemal Üniversitesi Sosyal Bilimler Enstitüsü Dergisi, 8(16), 195-223.

Trnova, E., \& Joseph. T. (2014). Implementation of creativity in science teacher training. International Journal on New Trends in Education and Their Implications, 5(3), 54-63. 
Torrance, E.P. (1977). Creativity in the classroom: what research says to the teacher. Washington: National Education Association. http://files.eric.ed.gov/fulltext/ED132593.pdf

Turan, M., \& Yıldırım, E., \& Tıkman, F. (2016). Öğretmen adaylarının eğitim ve bazı kavramlara ilişkin metaforik alg1lar1. Education Sciences, 11(4), 217-242.

Türer, A. (2009). Türkiye'de öğretmen yetiştirme ve sorunlar-I. http://w3.balikesir.edu.tr/ aturer/ogretmenyetistirme

Türkmen, N. (2014). Eğitim fakültesi ögrencilerinin eleştirel düşünme eğilimleri ve yaratıcılık düzeylerinin karşılaştırılması. [Yüksek lisans tezi]. Erciyes Üniversitesi, Eğitim Bilimleri Enstitüsü, Kayseri.

Vale, I., \& Barbosa, A. (2015). Mathematics creativity in elementary teacher training. Journal of the European Teacher Education Network, 10, 101-109.

Yenilmez, K., \& Yolcu, B. (2007) Öğretmen davranışlarının yaratıcı düşünme becerilerinin gelişimine katkısı. Osmangazi Üniversitesi Sosyal Bilimler Dergisi, 18, 95- 105. 


\section{EXTENDED ABSTRACT}

\section{Examination of the Relationship Between Creative Personality Traits and Creativity Support Skills of Classroom Teacher Candidates}

The aim of this study is to examine the relationship between creative personality traits of classroom teacher candidates and their ability to support creativity. In addition to this relationship, the creative personality skills and skills of classroom teacher candidates were examined according to the variants of class level, gender and type of school graduated. Classroom teachers who undertake the education of primary school age students where creativity is very high have a great responsibility to develop creativity (Iş1k, 2013). Teachers, who are considered role models by students, also increase the creativity of students in the educational process by showing behaviors that support creativity. It is important that classroom teachers who are together with students for 4 years during the primary school process engage in behaviors that support creativity (Özel \& Bayındır, 2015). The ability to support teachers with the level of creativity when looking at the studies that examine the relationship between creativity of Çağ Adıguzel (2016) and Pehlivan's (2019) work is seen as the closest research to the research carried out. But there was no study conducted on this issue with classroom teacher candidates. It is known that the education that teachers receive before service is important in terms of their behavior in the profession (K1liç, 2006). For this reason, in this research, the classroom teacher candidates were studied. The relationship between the creative personality traits of the classroom teacher candidates and their skills to support creativity, and in addition to this relationship, their creative personality traits and their skills to support creativity; It is thought that examining it according to the variables of level, gender and the type of school graduated from will contribute to the literature.Forthis purpose, 1, 2, 3 and 4 in the Department of primary education of the faculty of education of a state university located in the Mediterranean region. 244 classroom teachers who study at grade levels Constitution the candidate.

Participants were selected by the purpose sampling method and included in the research. Data in a study designed according to a relational screening model from quantitative research methods; researchers have developed a "personal information form", the Şahin \& Danışman (2007) developed by the "Creative Personality Traits Scale" and Soh (2000) the "Teacher Index Scale Supporting Creativity" developed by Soh (2000) and adapted to Turkish by Dikici (2013) were collected. The personal information form contains questions about the gender of prospective teachers, class level, and the types of schools they graduated from. Scale of creative personality traits developed by Şahin \& Danışman (2007); It was developed with the aim of measuring creative personality traits that reflect Turkish culture. Validity and reliability studies of the scale were conducted with a group of high school and university students. A four-factor structure consisting of 17 items was obtained as a result of an explanatory factor analysis conducted to examine the validity of the structure. From the scale assessed on the total score, the lowest score that can be obtained is 17 , and the highest score is 85 . The high value of the score taken from the scale indicates the height of the creative personality trait. The teacher Index scale supporting creativity, developed by Soh (2000), was adapted into Turkish by Dikici (2013). The scale working group consists of 288 teachers working in different branches. In the explanatory factor analysis, the Turkish form of the scale was found to have 33 substances and nine sub-dimensions. If the cronbach Alpha reliability coefficient obtained from the entire scale .96. Data from scales; In the selection of tests to be applied, parametric tests were sought, 
parametric tests were used in cases that provide the conditions, and non-parametric tests were used in cases that do not provide the conditions.

According to the results of the research; A simple linear correlation aimed at revealing the relationship between the creative personality traits of classroom teacher candidates and their ability to support creativity was studied using the Pearson correlation multiple number. According to the analysis, there is a positive, very high level of significant relationship between the creative personality traits of the classroom teacher candidates and their ability to support creativity. According to the results of multiple comparisons with the Mann-Whitney U test to determine which grade levels the differences were between grade levels 1-3,1-4 and 2-3, 2-4. An analysis of prospective teachers by gender creative personality traits scores for independent samples t-test obtained from the scores of men and women as a result of no significant difference between the scores of the prospective teachers did not have a significant impact on the personality traits and gender, it is seen that creative. Scores of prospective teachers according to the type of the Graduate School of creative personality traits for an analysis Kruskal-Wallis test, as a result of the type of school that does not cause a significant difference on scores of prospective teachers of creative personality traits reveals. The ability to support the creativity of prospective teachers according to grade level scores for analysis of KruskalWallis tests as a result of the ability to support the creativity of participants in four different grade levels observed differences between grade levels in which a statistically significant difference between the scores is performed to ascertain that the Mann-Whitney $U$ test for multiple comparisons according to the results, differences, and across grade levels 1-4 and 2-4 were. Independent samples conducted to examine the creativity support scores of classroom teacher candidates by gender showed no significant difference between the scores obtained from women and men as a result of the T-test. The ability to support the creativity of prospective teachers according to the type of the scores of the Graduate School for an analysis KruskalWallis test, as a result of scores of prospective teachers the ability to support the creativity of the type of school that does not cause a significant difference on the reveals. The results of the research were compared, discussed and interpreted with similar research results. In light of the results obtained from the research, it may be recommended to add compulsive or selective courses to the license program of classroom teaching that will contribute to the development of the level of creativity.

"International Journal of New Approaches in Social Studies - IJONASS" is licensed under a Creative Commons Attribution-NonCommercial-ShareAlike 4.0 International License. 